\title{
O PROGRAMA BOLSA ATLETA NO CONTEXTO ESPORTIVO NACIONAL
}

\author{
Marcelo Resende Teixeira' \\ Wagner Barbosa Matias² \\ Fernando Henrique Carneiro ${ }^{3}$ \\ Fernando Alves Mascarenhas ${ }^{4}$
}

\section{RESUMO}

Este estudo objetiva analisar o Programa Bolsa Atleta, a partir de sua abrangência, assim como a configuração de seu financiamento e gasto, cotejando tais dados com os principais resultados alcançados nos Jogos Olímpicos de Pequim 2008, Londres 2012 e Rio de Janeiro 2016. A investigação é caracterizada como quantitativo-qualitativa e de cunho documental. Os dados foram coletados nas seguintes fontes: a) Portal da Transparência do Governo Federal; b) relação dos atletas beneficiados no Diário Oficial da União; c) dados de relatórios de gestão do Ministério do Esporte e do Comitê Olímpico do Brasil; d) site dos Jogos Olímpicos de Pequim, Londres e Rio de Janeiro. Como resultado, percebeu-se que o investimento do Programa é realizado em atletas já prontos, e mesmo assim tal situação tem gerado resultados tímidos na evolução histórica da delegação brasileira nos últimos três Jogos Olímpicos5.

Palavras-chave: Políticas Públicas. Políticas Esportivas. Bolsa Atleta.

1 Mestre em Educação Física. Professor da Secretaria de Educação do Distrito Federal e servidor do Ministério do Esporte. Brasília/Distrito Federal, Brasil. E-mail: marinresende@yahoo.com.br

2 Doutorando em Educação Física. Professor da Secretaria de Educação do Distrito Federal e servidor do Ministério do Esporte. Universidade de Brasília (UnB). Brasília/Distrito Federal, Brasil. E-mail: wagner.matias@outlook.com

3 Doutorando em Educação Física. Professor do Instituto Federal de Educação, Ciência e Tecnologia de Goiás (IFG). Universidade de Brasília (UnB). Senador Canedo/Goiás, Brasil. E-mail: fernandohenriquesc@gmail.com

4 Doutor em Educação Física. Professor da Universidade de Brasília (UnB). Brasília/Distrito Federal, Brasil. E-mail: fernando.masca@outlook.com

5 Não há conflitos de interesse de natureza pessoal, comercial, política, acadêmica ou financeira neste texto, bem como não houve auxílio financeiro recebido para a elaboração do estudo que deu origem ao artigo. 


\title{
ATHLETE ASSISTANCE PROGRAM IN SPORTS NATIONAL CONTEXT
}

\begin{abstract}
This study aims to analyze the Scholarship Athlete from its coverage, as well as the configuration of their funding and spending, comparing these data with the main achievements in the Olympic Games of Beijing 2008, London 2012 and Rio de Janeiro, 2016. The research is characterized as quantitative, qualitative and documentary nature. Data were collected from the following sources: a) Transparency Portal of the Federal Government; b) list of athletes benefited in the Official Gazette; c) Data ME management reports and $\mathrm{COB}$; d) site of the Olympic Games in Beijing, London and Rio de Janeiro. As a result, it was realized that the investment program is carried out on ready-made athletes; and yet this situation has generated poor results in the historical evolution of the Brazilian delegation in the last three Olympic Games.
\end{abstract}

Keywords: Public Policy. Sports Policies. Athlete Assistance.

\section{EL PROGRAMA BOLSA ATLETA EN EL CONTEXTO DEPORTIVO NACIONAL}

\section{RESUMEN}

En este estudio se pretende analizar la Bolsa Atleta de su ámbito, así como la configuración de su financiación y el gasto, la comparación de estos datos con los principales logros en los Juegos Olímpicos de Pekín 2008, Londres 2012 y Río de Janeiro, 2016. la investigación se caracteriza como la naturaleza cuantitativa, cualitativa y documental. Los datos se obtuvieron de las siguientes fuentes: a) Portal de Transparencia del Gobierno Federal; b) la lista de los atletas se benefició en el Boletín Oficial; c) los informes de gestión de datos y ME COB; d) El sitio de los Juegos Olímpicos de Beijing, Londres y Río de Janeiro. Como resultado, se observó que el programa de inversión se lleva a cabo en los atletas ya preparadas y sin embargo, esta situación ha generado pobres resultados en la evolución histórica de la delegación brasileña en los últimos tres Juegos Olímpicos.

Palabras clave: Políticas Públicas. Políticas Deportivas. Bolsa Atleta. 


\section{INTRODUÇÃO}

O financiamento é elemento essencial na implementação de políticas públicas, uma vez que, embora este não fosse o único critério de análise de uma política ou programa social, sua composição e destinação são fortes indicadores das prioridades da ação governamental, bem como expressa a correlação de forças entre as classes para se atingir tal finalidade (SALVADOR, 2008; ATHAYDE, 2011).

Para Fagnani (2009), o estudo do financiamento permite obter o conhecimento sobre o tipo de articulação existente entre a política pública preconizada e os demais setores da sociedade envolvidos, ressaltando se há ocorrência ou não de uma desproporção entre os recursos aplicados em determinados programas e seus resultados.

Nesses termos, a produção acadêmica no âmbito do financiamento do esporte no Brasil tem aumentado nos últimos anos. Os estudos de Veronez (2005), Castelan (2010), Almeida (2010), Athayde (2013), Teixeira, Matias e Mascarenhas (2013) e Mascarenhas (2016)6 são alguns deles. Já em relação ao Bolsa Atleta, destacam-se os trabalhos realizados por Guimarães (2009) e Corrêa et al. (2014).

Assim, numa análise de tais estudos, fica o alerta que o gasto estatal e a definição das fontes de recursos não seguem apenas critérios econômicos, mas, também, a preponderância ocorre a partir dos critérios políticos, refletindo, portanto, o processo de correlação de forças existente na sociedade e invariavelmente atendendo a classe dominante (ATHAYDE, 2013).

Na materialização dessas disputas no campo esportivo, de acordo com Manhães (2002), até a Constituição Federal (CF) de 1988 todas as medidas do Estado no campo esportivo foram originárias do Estado Novo, com alterações periféricas ou formais, pautadas nos princípios nacionalista e disciplinador. Apenas em 1988, com a promulgação da CF é que o Estado assume, pelo menos formalmente, a responsabilidade de promover o acesso dos brasileiros às diversas manifestações esportivas como direito social.

No entanto, a CF de 1988 ao passo que estabelece o esporte como um direito, dá autonomia para as entidades esportivas, cedendo à pressão delas, bem como do universo dos negócios no mercado esportivo por mais liberdade de atuação, tendo em vista que, à época da confecção da carta Magna, o Conselho Nacional de Desporto (CND) ainda tinha plenos poderes de intervenção (OURIQUES, 1999). Sobre esse aspecto, o esporte no Brasil:

\footnotetext{
Não passou alheio e tampouco ficou imune às transformações e investidas do Estado brasileiro. Foi um setor (e continua sendo, em que pese a autonomia conferida pela Constituição de 1988), quando não sob intervenção, substancialmente influenciado e dependente do governo, de instituições e empresas estatais, sobretudo no que diz respeito a sua sustentabilidade financeira (VERONEZ, 2005, p. 48).
}

6 MASCARENHAS, F. 2016. O orçamento do esporte 2001-2012: Aspectos da atuação estatal de FHC à Dilma. Artigo não publicado. 
Dessa forma, o Estado deixa de ser o "ator principal", abandonando o "intervencionismo" político característico das legislações anteriores. Porém, a administração pública continuou a financiar o esporte de alto rendimento-espetáculo, mas a gestão e o estabelecimento de critérios de distribuição dos recursos ficavam a cargo das federações, confederações e do Comitê Olímpico do Brasil (COB). "O Estado sai de cena", as entidades esportivas passam a ter autonomia, sem abrir mão do fundo público (CASTELLANI FILHO, 2008).

Desse modo, o resultado negativo do Brasil no quadro de medalhas nos Jogos Olímpicos de Sidney (2000) provocou um intenso debate no seio do campo esportivo e do Governo Federal7. Conforme Bracht e Almeida (2003), tal cenário foi o suficiente para o desencadeamento de um movimento "em favor" da educação física, sendo que dois segmentos reivindicaram protagonismo nesse processo: trata-se dos interesses do sistema esportivo e dos interesses corporativos da educação física8. O impacto e o respaldo dessa orientação para as políticas públicas culminaram, segundo os autores, em uma pseudovalorização da Educação Física, ou seja, ao subordinar a Educação Física aos interesses, por exemplo, do alto rendimento, tornam-se claros dois aspectos, a perda do projeto político-pedagógico desta disciplina e a subordinação desta à política esportiva.

Nessa política esportiva, ao longo da primeira década do século XXI, a União diversificou as fontes de financiamento do esporte9, bem como vinculou recursos ao setor, uma vez que sancionou diversos ordenamentos legais, como: Lei $n^{\circ}$ 10.264/2001 (Agnelo-Piva), Lei $n^{\circ}$ 10.891/2004 (Bolsa Atleta) e Lei no 11.438/2006 (Lei de Incentivo ao Esporte). Dentre a legislação citada, aquela que atende diretamente a demanda dos atletas de alto rendimento é o Programa Bolsa Atleta.

A Lei instituída em 2004 e regulamentada em janeiro de 2005 pelo Decreto n 5.34210 prevê a distribuição de bolsas em seis níveis: Atleta de Base, Estudantil, Nacional, Internacional, Olímpico e Atleta Pódio11. O governo brasileiro considera o Bolsa Atleta como o maior programa de financiamento individual de atletas do mundo12. O público alvo do Programa Bolsa Atleta são os atletas de modalidades olímpicas e paralímpicas,

7 “Brasil, após ano perdido, segue sem rumo olímpico". Folha de S. Paulo, 26 ago. 2001. Disponível: http:// www1.folha.uol.com.br/fsp/esporte/fk2608200120.htm?mobile. Acesso em: 30 set. 2016.

8 Representados pelo Conselho Federal de Educação Física (Confef).

9 Ressalta-se que as fontes vinculadas ao orçamento do esporte são orçamentárias, aquelas cujos recursos transitam pelo orçamento federal; extraorçamentárias, cujos recursos são repassados diretamente às entidades esportivas; indiretas, cujos recursos são provenientes de desoneração tributária. Portanto, o Bolsa Atleta não se caracteriza como uma fonte de financiamento, e, sim, como um instrumento de direcionamento.

10 Segundo Guimarães (2009), as discussões, em particular sobre a dificuldade de patrocínio aos atletas nacionais, foram iniciadas pelo então deputado Agnelo Queiroz, nos anos 2000, culminando com a apresentação de projeto de Lei que instituía a Lei do Bolsa Atleta naquele ano. A tramitação na Câmara dos Deputados foi demorada, sendo a votação da redação final na Comissão de Constituição e Justiça e de Cidadania da Câmara dos Deputados realizada apenas em 30 de março de 2004. A tramitação no Senado Federal foi mais célere e sem alterações ao texto recebido da Câmara.

11 A Lei 12.395/2011 atualizou a legislação anterior do Programa, no entanto, apenas contempla atletas individuais. 
bem como aqueles de modalidades vinculadas ao Comitê Olímpico Internacional (COI) e ao Comitê Paralímpico Internacional (IPC) que obtém bons resultados em competições locais, sul-americanas, pan-americanas, mundiais, olímpicas e paralímpicas, de suas respectivas modalidades.

No caso das modalidades que não são olímpicas e paralímpicas, o atleta deverá ser indicado por entidades nacionais dos respectivos esportes, referendadas por histórico de resultados, submetidas ao Conselho Nacional de Esporte (CNE), para que sejam observadas as prioridades de atendimento à Política Nacional de Esporte (PNE) e às disponibilidades financeiras (GUIMARÃES, 2009).

Destaca-se que a Lei 12.395/2011 alterou o Programa Bolsa Atleta ao garantir que os atletas com patrocínio privado também tivessem o direito de pleitear e receber o apoio do Programa. Além disso, a referida Lei limitou em 15\% do valor total a ser repassado para os atletas de modalidades que não são olímpicas.

Atualmente, de acordo com página oficial do Programa13, as categorias, o pré-requisito, bem como o valor mensal recebido em cada uma das bolsas oferecidas pelo Ministério do Esporte, são:

- Atleta de Base: a) idade mínima de 14 anos e máxima de 19 anos; b) estar vinculado a uma entidade de prática desportiva (clube); c) ter filiação à Entidade de Administração de sua modalidade, tanto Estadual (Federação) como Nacional (Confederação); d) ter participado de competição no ano imediatamente anterior àquele em que está pleiteando a Bolsa, tendo obtido até a terceira colocação nas modalidades individuais de categorias e eventos previamente indicados pela respectiva entidade nacional de administração do desporto ou que tenham sido eleitos entre os dez melhores atletas do ano anterior em cada modalidade coletiva, na categoria indicada pela respectiva entidade e que continuem treinando e participando de competições nacionais oficiais. Valor mensal do benefício: R\$ 370,00. Registre-se que a criação da categoria Atleta de Base foi uma das modificações no programa introduzidas pela Lei 12.395/2011, sancionada em março daquele ano pela ex-presidenta Dilma Rousseff. Conhecida como a Lei do Atleta, tal legislação cria bases para redimensionar os investimentos no sentido de posicionar o Brasil entre os principais países com resultados esportivos positivos, uma vez que coloca o foco do programa Bolsa-Atleta nas práticas esportivas de alto rendimento, ou seja, nas modalidades que compõem o programa dos Jogos Olímpicos e Paraolímpicos. Acrescenta-se ainda a permissão aos atletas patrocinados de também terem direito ao beneficio da Bolsa-Atleta, fato até então proibido.

- Atleta Estudantil: a) idade mínima de 14 anos e máxima de 20 anos; b) estar regularmente matriculado em instituição de ensino, pública ou privada; c) ter participado de competição no ano imediatamente anterior àquele em que está pleiteando a Bolsa, tendo obtido a seguinte classificação: Esportes Individuais (classificado de 
$\mathbf{1}^{\mathbf{0}}$ a $3^{\mathbf{0}}$ lugar nos Jogos Estudantis Nacionais organizados e homologados pelo Ministério do Esporte). Esportes Coletivos (seis melhores atletas em cada modalidade coletiva). Valor mensal do benefício: R\$ 370,00.

- Atleta Nacional: a) maior de 14 anos; b) estar vinculado a uma entidade de prática desportiva (clube); c) ter filiação à Entidade de Administração de sua modalidade, tanto Estadual (Federação) como Nacional (Confederação); d) ter participado de competição no ano imediatamente anterior àquele em que está pleiteando a Bolsa, tendo obtido a seguinte classificação: De $\mathbf{1}^{\mathbf{0}}$ a $3^{\circ}$ lugar no evento máximo nacional organizado e indicado pela Entidade Nacional de Administração de sua modalidade ou de $1^{\circ}$ a $3^{\circ}$ lugar no ranking nacional por ela organizado e indicado. Valor mensal do benefício: $\mathbf{R} \$ \mathbf{9 2 5 , 0 0}$.

- Atleta Internacional: a) maior de 14 anos; b) estar vinculado a uma entidade de prática desportiva (clube); c) ter filiação à Entidade de Administração de sua modalidade, tanto Estadual (Federação) como Nacional (Confederação); d) ter participado de competição internacional, indicada pela Entidade Nacional, no ano imediatamente anterior àquele em que está pleiteando a bolsa, tendo obtido a seguinte classificação: De $1^{\circ}$ a $3^{\circ}$ lugar em Campeonatos Mundiais; de $1^{\circ}$ a $3^{\circ}$ lugar Jogos ou Campeonatos Pan-americanos e Parapan-americanos ou de $1^{\circ}$ a $3^{\circ}$ lugar Jogos ou Campeonatos Sul-americanos. Valor mensal do benefício: R\$ 1.850,00.

- Atleta Olímpico: a) maior de 16 anos; b) estar vinculado a uma entidade de prática desportiva (clube); c) ter filiação à Entidade de Administração de sua modalidade, tanto em nível Estadual (Federação) como Nacional (Confederação); d) ter integrado na qualidade de atleta a delegação brasileira (como titulares em modalidades individuais ou com seus nomes presentes nas súmulas de modalidades coletivas na última edição dos Jogos Olímpicos ou Paralímpicos; e) nos três anos subsequentes ao dos Jogos Olímpicos ou Paralímpicos, continuar participando de competições internacionais indicadas pelo respectivo comitê. Valor mensal do benefício: R\$ 3.100,00.

- Atleta Pódio: os valores mensais flutuam de $\mathbf{R} \$ \mathbf{5 . 0 0 0 , 0 0}$ a $\mathbf{R} \$ \mathbf{1 5 . 0 0 0 , 0 0}$, sendo os critérios de acesso e permanência variados e modificados desde sua implantação em $2013^{14}$. Ressalta-se que esta categoria possibilita contratação de técnicos e equipes multidisciplinares, compra de equipamentos e materiais e viagens para treinamentos e competições.

Os beneficiados pelo Bolsa-Atleta recebem a ajuda durante um ano, sendo o dinheiro depositado em conta específica do atleta. A prioridade são os atletas de esportes que compõem os programas dos Jogos Olímpicos. Em seguida, o benefício se destina aos atletas de modalidades chamadas não olímpicas (que compõem o programa dos Jogos Pan-americanos e outras que não fazem parte dessas competições).

Diante de tal cenário, o objetivo deste estudo é analisar o Programa Bolsa Atleta, a partir da abrangência e da configuração do gasto, além disso, cotejar o quantitativo de 
bolsas, com os resultados alcançados nos Jogos Olímpicos de Pequim 2008, Londres 2012 e Rio de Janeiro.

\section{PROCEDIMENTOS METODOLÓGICOS}

Nesta investigação a abordagem é de caráter quantitativo-qualitativo, apoiando-se em levantamento documental de fontes primárias e secundárias, bem como pesquisas bibliográficas consubstanciadas em levantamentos da documentação referente ao assunto (SÁ SILVA; ALMEIDA; GUINDANI, 2009).

Os dados foram coletados a partir das seguintes fontes: a) Portal da Transparência do Governo Federal; b) relação dos atletas beneficiados no Diário Oficial da União; c) dados de relatórios de gestão do Ministério do Esporte (ME) e do COB; d) site dos Jogos Olímpicos de Pequim, Londres e Rio de Janeiro. O recorte do estudo corresponde ao período de janeiro de 2005 até dezembro de 2015, ou seja, dez anos, além disso, se justifica pelo início da implementação do próprio Programa Bolsa Atleta e por perpassar o período de preparação e de realização dos Jogos Olímpicos de Pequim 2008, Londres 2012 e Rio de Janeiro 2016.

Para a análise e discussão foi adotado o método de análise de políticas sociais proposto por Boschetti (2009), com atenção para a "configuração do financiamento e gasto", em que foram utilizados os indicadores de magnitude e direcionamento do gasto com programa, assim como a "configuração e abrangência dos direitos e benefícios", em que foi feito uso do indicador abrangência.

Sob o aspecto monetário aplicou-se para deflacionar as despesas o Índice Geral de Preços - Disponibilidade Interna (IGP-DI), calculado pela Fundação Getúlio Vargas (FGV)15. Para operá-lo, utilizamos a Calculadora do Cidadão, disponível no portal do Banco Central do Brasil (BCB). Essa escolha se justifica devido à ausência de índice próprio de custos dos serviços públicos de esporte, de modo que os recursos entre anos possam se tornar comparáveis.

Sinteticamente, o trabalho é composto pela introdução e deneliamento metodológico, seguido por um debate sobre a configuração do financiamento e gasto do Programa Bolsa Atleta intercalados com uma reflexão a respeito dos principais resultados conquistados pela delegação brasileira nos Jogos Olímpicos de Pequim 2008, Londres 2012 e Rio de Janeiro 2016. Por fim, seguem as considerações finais, bem como as referências bibliográficas utilizadas. 


\section{O Bolsa Atleta em números...}

Registre-se que no montante destinado pelo Bolsa Atleta estão inclusos os gastos diretos $^{16}$ do Governo Federal com atletas de diferentes modalidades e níveis, não sendo possível, dessa forma, a separação a partir dos dados disponíveis no Portal da Transparência. Neste sentido, no período de 2005 a 2015, conforme dados do portal, o montante destinado ao Bolsa Atleta foi de R\$823.1 milhões, ou seja 17\% do orçamento ministerial do período17. A evolução ano a ano é demonstrada na tabela 1:

Tabela 1 - Gastos diretos por programas do Ministério do Esporte e Bolsa Atleta - série 2005-2015 (valores pagos e deflacionados pelo IGP-DI em R \$ milhões).

\begin{tabular}{cccc}
\hline Ano & Ministério do esporte & Bolsa atleta & \% \\
\hline $\mathbf{2 0 0 5}$ & Bloco 1 - PPA 2004-2007 & $21 \%$ \\
$\mathbf{2 0 0 6}$ & 13.7 & 2.9 & $47 \%$ \\
$\mathbf{2 0 0 7}$ & 41.7 & 19.8 & $53 \%$ \\
\hline \multicolumn{4}{c}{ Bloco 2 - PPA 2008-2011 } \\
\hline $\mathbf{2 0 0 8}$ & 40.3 & 21.5 & $43 \%$ \\
$\mathbf{2 0 0 9}$ & 92.1 & 39.8 & $21 \%$ \\
$\mathbf{2 0 1 0}$ & 260.1 & 55.6 & $9 \%$ \\
$\mathbf{2 0 1 1}$ & 759.7 & 69.3 & $6 \%$ \\
\hline \multicolumn{3}{c}{ Bloco 3 - PPA 2012-2015 } & 69.3 \\
\hline $\mathbf{2 0 1 2}$ & 1.248 .9 bi & 96.3 & $26 \%$ \\
$\mathbf{2 0 1 3}$ & 374.3 & 128.4 & $26 \%$ \\
$\mathbf{2 0 1 4}$ & 498.6 & 224.9 & $27 \%$ \\
$\mathbf{2 0 1 5}$ & 836.6 & 94.9 & $13 \%$ \\
\hline TOTAL & 717.0 & $\mathbf{8 2 3 . 1}$ & $\mathbf{1 7 \%}$ \\
\hline
\end{tabular}

Fonte: Portal da Transparência. Elaboração dos autores (2016).

A divisão por blocos facilita a compreensão quanto à magnitude dos gastos em cada Plano Plurianual/PPA18. Portanto, considerando os anos do Bloco 1, nota-se um crescimento ao longo dos anos. Quando o comparativo se realiza com os recursos pagos para os demais programas finalísticos19, das três dimensões esportivas no orçamento do

16 Ver Glossário, presente no "Portal da Transparência" do Governo Federal. Disponível em: http://www. portaldatransparencia.gov.br/glossario/. Acesso em: 15 set. 2016.

17 Considerando os vários estágios do orçamento federal, os dados deste estudo se referem aos valores efetivamente pagos, ou seja, somente aqueles em que houve de fato desembolso ao beneficiário.

18 O PPA, com vigência de quatro anos, tem como função estabelecer as diretrizes, objetivos e metas de médio prazo da administração pública.

19 Os programas com mais evidência de cada secretaria finalística à época eram: Programa Segundo Tempo, 
ME, o Bolsa Atleta correspondeu à parte significativa, a saber: $21 \%, 47 \%$ e $53 \%$ respectivamente aos anos de 2005, 2006 e 2007.

Quanto ao Bloco 2, também se verifica crescimento dos recursos em toda série correspondente ao período. No tocante aos gastos diretos por programas do Ministério do Esporte no período do segundo bloco há uma diminuição considerável, pois se inicia em 2008 com $43 \%$ do orçamento, e cai drasticamente nos anos subsequentes para $21 \%$, $9 \%$ e $6 \%$, simultaneamente. Todavia, cabe ressaltar que o orçamento ministerial cresceu consideravelmente nos últimos anos do bloco, muito influenciado pela realização dos Jogos Mundiais Militares em 2011, e pela preparação dos atletas para disputa dos Jogos de Londres em 2012 (ATHAYDE, 2013).

Em relação ao Bloco 3, do mesmo modo se verifica crescimento dos recursos, exceto no período entre 2014 e 2015, no qual se percebe uma pequena redução. Contudo, tal diferença não teve interferência significativa na manutenção e/ou ampliação do programa ao longo dos anos, pois, conforme veremos adiante, não houve oscilação significativa do número de beneficiados.

No período constata-se novo aumento de recursos do programa, contudo, percebe-se que os gastos por programas do Ministério do Esporte reduziram admiravelmente por algumas razões, a saber: a) término dos investimentos nos jogos militares; b) realização da Copa FIFA e das Olimpíadas; c) troca de gestores da pasta. Para Carneiro (2016)20, tal fato pode ser também explicado quando se analisa orçamento do Ministério do Esporte de maneira ampla, pois à medida que os valores gastos com as áreas finalísticas foram diminuindo, os gastos com os Megaeventos foram aumentando, notadamente a partir do PPA 2012/2015.

Ainda sobre as seguidas trocas dos gestores da pasta esportiva é oportuno realizarmos um resgate histórico, pois desde o fim de 2011 o ME sofreu várias alterações em seu comando. Em substituição a Orlando Silva, vinculado ao Partido Comunista do Brasil (PCdoB) e exonerado após denúncias de desvio de recursos públicos, o ME fora conduzido por vários gestores; sendo o primeiro o Deputado Aldo Rebelo (PCdoB), o qual ficou no cargo até sua nomeação no Ministério de Ciência, Tecnologia e Inovação após reforma ministerial realizada pela até então presidente Dilma Rousseff em 2015. Cabe mencionar o tímido relacionamento para com o esporte na trajetória política, pessoal e profissional de tais ministros até assumirem o ME.

Depois dele, no sentido de alinhamento e sustentação política com a base aliada, o ME foi entregue ao Partido Republicano do Brasil (PRB21); findando com a chegada

Programa Esporte e Lazer da Cidade e Programa Rumo ao Pan. O decreto $\mathrm{n}^{\circ} 4.668$, de abril de 2003, criou a estrutura e os órgãos do Ministério do Esporte, que sob o comando PCdoB, desde 2003 até a saída de Aldo Rebelo, possui atualmente três secretarias finalísticas (Secretaria Nacional de Esporte, Educação, Lazer e Inclusão Social-SNELIS; Secretaria Nacional do Esporte de Alto Rendimento-SNEAR; e, Secretaria Nacional do Futebol e Direitos do Torcedor). Entretanto, até início de 2011, tínhamos as seguintes secretarias: Secretaria Nacional do Esporte Educacional-SNEED; Secretaria Nacional de Desenvolvimento do Esporte e Lazer- SNDEL e a SNEAR, que continua.

20 CARNEIRO, F. H. 2016. O orçamento do esporte no PPA - 2012/2015. Artigo não publicado.

21 Ao término das eleições de 2014, o PRB aumentou consideravelmente sua bancada na Câmara passando de 10 para 21 deputados. Disponível em http://www.prb10.org.br/noticias/parlamentares/meta-ultrapassada-prbelege-21-deputados-federais-e-aumenta-bancada-estadual-para-31/. Acesso em 09 dez. 2016. 
do também Deputado George Hilton à gestão da pasta. Nem o PRB, muito menos Hilton possuíam relações com o esporte, mas pela proximidade e visibilidade dos jogos Rio 2016 o ME era um bom palco. O referido ministro deixou o cargo após o PRB romper com o governo em março de 201622, bem como devido à saída do Partido do Movimento Democrático Brasileiro (PMDB) da base; diante de um cenário de instabilidade política, traumático, controverso e com diversas análises. Em meio ao processo de recomposição do governo assumiu a pasta interinamente o à época secretário nacional de Esporte de Alto Rendimento, Ricardo Leyser.

O cenário de crise anunciado culminou com processo de impedimento contra o governo Dilma, tal fato propiciou nova mudança na gestão esportiva uma vez que ao assumir o país Michel Temer, mesmo interinamente naquele momento, promoveu uma ampla reforma ministerial e ao PMDB coube o ME. Assim, em maio de 2016, o Deputado Leonardo Picciani foi nomeado para ser até o presente momento o mandatário maior do órgão. Natural de Nilópolis/RJ e com forte tradição familiar na política local sua indicação passou pela necessidade de facilitar as articulações a nível federal em favor dos jogos Rio 2016, tendo em vista que o PMDB já controlava o município e o estado do Rio de Janeiro. Picciani como os outros não têm vínculos consistentes com o esporte, e contraditoriamente votou contra o impedimento de Dilma embora fosse líder do PMDB na Câmara.

No que se refere à abrangência do programa, novamente recorremos à Boschetti (2009), sendo que o principal elemento que compõe esse indicador é o número de beneficiados, todavia, como ressalta a autora, apenas este aspecto isoladamente não revela, necessariamente, o que se quer demonstrar. Assim, no sentido de aproximarmos do real a tabela 2 consolida as informações coletadas, conforme a seguir:

22 Registre-se que no intuito de permanecer no cargo o referido ministro trocou o PRB pelo Partido Republicano da Ordem Social (PROS), porém uma semana depois foi exonerado do cargo. Disponível em http://www1.folha. uol.com.br/esporte/olimpiada-no-rio/2016/03/1755759-governo-oficializa-saida-de-george-hilton-do-ministeriodo-esporte.shtml. Acesso em: 09 dez. 2016. 
Tabela 2 - Número de atletas contemplados pelo Bolsa Atleta em todas as categorias.

\begin{tabular}{cc}
\hline Atletas Beneficiados pelo Programa Bolsa-Atleta Geral (2005-2015) \\
\hline $\mathbf{2 0 0 5}$ & 975 \\
$\mathbf{2 0 0 6}$ & 854 \\
$\mathbf{2 0 0 7}$ & 2.171 \\
$\mathbf{2 0 0 8}$ & 3.313 \\
$\mathbf{2 0 0 9}$ & 2.949 \\
$\mathbf{2 0 1 0}$ & 3.655 \\
$\mathbf{2 0 1 1}$ & 4.858 \\
$\mathbf{2 0 1 2}$ & 5.777 \\
$\mathbf{2 0 1 3}$ & 6.756 \\
$\mathbf{2 0 1 4}$ & 7.616 \\
$\mathbf{2 0 1 5}$ & 7.322 \\
\hline TOTAL & $\mathbf{4 6 . 2 4 6}$ \\
\hline
\end{tabular}

Fonte: http://www2.esporte.gov.br/snear/bolsaAtleta/listaContemplados.jsp. Elaboração dos autores (2016).

Considerando o número de atletas atendidos por ano pelo Bolsa Atleta podemos afirmar que sua abrangência é restrita. Tal afirmação é convalidada pelo estudo publicado no Atlas do Esporte Brasileiro, pois, o potencial de atletas de alto nível de um país corresponde a $2 \%$ da população (COSTA, 2006). Deste modo, o Brasil, com cerca 200 milhões de habitantes23, teria, em tese, 4 milhões de esportistas de alto rendimento e o programa em dez anos contemplou apenas 46.246 bolsas. No ano de 2014, ápice da série histórica, o número de beneficiados foi de somente 7.61624 .

Não obstante, como se observa abaixo, à exceção dos anos 2006, 2009 e 2015, houve um incremento constante do número de beneficiados pela Bolsa-Atleta desde sua implantação em 2005. A oscilação desses anos pode estar relacionada com as características do próprio programa, tendo em vista os vários requisitos cumulativos, tratados outrora, aos quais os atletas devem atentar para a obtenção da bolsa, ou seja, não há garantia de continuidade do recebimento do benefício, tendo o programa grande possibilidade de exclusão. O referido aspecto é crucial para entendimento amplo de uma política pública, conforme a seguir:

23 De acordo com dados do site do Instituto Brasileiro de Geografia e Estatística. Disponível em: http://www.ibge. gov.br/home/. Acesso em: 17 set. 2016.

24 Em valores aproximados o número de atletas favorecidos ano a ano foi de 4.204, bem abaixo do potencial sugerido pelo estudo do Atlas do Esporte Brasileiro. 
Os critérios de acesso e permanência dos cidadãos em determinada política e/ou programa social são reveladores de sua intencionalidade e capacidade de inclusão e/ou exclusão do acesso. Quanto mais rigorosos e restritos forem os critérios de acesso e permanência, mais focalizados e seletivos a política e/ou programa tende a ser (BOSCHETTI, 2009, p.12).

Tal fato também fere um dos princípios básicos da administração esportiva, como planejamento estratégico, de médio e longo prazo, pois limita em apenas um ano a garantia do recebimento dos recursos, afetando diretamente no ponto central do programa, ou seja, a garantia de condições mínimas para que se dediquem, com exclusividade e tranquilidade, aos treinamentos25 (CHARNOV; MONTANA, 2001).

No tocante ao número de atletas beneficiados, optou-se por decompor as informações nas categorias do programa, em um primeiro momento, não separando os números em esportes olímpicos e paralímpicos ou não olímpicos e paralímpico, para que em um segundo momento fossem mencionados os dados com esta divisão. A tabela 3 apresenta os dados encontrados.

Tabela 3 - Número de atletas do Bolsa Atleta divididos por categorias.

\begin{tabular}{ccccccc}
\hline \multicolumn{6}{c}{ Atletas Beneficiados por Categoria Geral em todas as Modalidades (2005-2015) } \\
\hline Ano & Base $^{\mathbf{2 6}}$ & Estudantil & Nacional & Internacional & Olímpica & Pódio \\
\hline $\mathbf{2 0 0 5}$ & - & 110 & 423 & 357 & 85 & - \\
$\mathbf{2 0 0 6}$ & - & 104 & 207 & 440 & 103 & - \\
$\mathbf{2 0 0 7}$ & - & 286 & 1.109 & 663 & 113 & - \\
$\mathbf{2 0 0 8}$ & - & 167 & 2.055 & 962 & 129 & - \\
$\mathbf{2 0 0 9}$ & - & 130 & 1.573 & 809 & 437 & - \\
$\mathbf{2 0 1 0}$ & - & 232 & 2.439 & 799 & 185 & - \\
$\mathbf{2 0 1 1}$ & 203 & 216 & 2.895 & 1.260 & 284 & - \\
$\mathbf{2 0 1 2}$ & 211 & 211 & 3.588 & 1.480 & 287 & - \\
$\mathbf{2 0 1 3}$ & 268 & 233 & 4.294 & 1.414 & 389 & 158 \\
$\mathbf{2 0 1 4}$ & 293 & 317 & 4.633 & 1.942 & 248 & 183 \\
$\mathbf{2 0 1 5}$ & 273 & 327 & 4.583 & 1.709 & 236 & 194 \\
\hline TOTAL & $\mathbf{1 . 2 4 8}$ & $\mathbf{2 . 3 3 3}$ & $\mathbf{2 7 . 7 9 9}$ & $\mathbf{1 1 . 8 3 5}$ & $\mathbf{2 . 4 9 6}$ & $\mathbf{5 3 5}$ \\
\hline
\end{tabular}

Fonte: http://www2.esporte.gov.br/snear/bolsaAtleta/listaContemplados.jsp. Elaboração dos autores (2016).

25 Como já constatou o Tribunal de Contas da União (TCU) em auditoria, quando revelou a demora entre o pedido da concessão do benefício e a liberação da primeira parcela. Disponível em http://josecruz.blogosfera.uol.com. br. Acesso em: 22 set. 2016.

26 Categoria criada apenas em 6/10/2011, por meio da Portaria $n^{\circ} 164 / 2011$, que estabeleceu as fases do pleito, os procedimentos de inscrição, os critérios para indicação de eventos esportivos e os critérios objetivos para concessão da Bolsa-Atleta e deu outras providências. 
Os dados revelam uma oscilação pequena, ora a maior, ora a menor, no número de bolsas dentro das categorias, todavia, com um direcionamento expressivo ao esporte profissional quando a comparação é entre as categorias, pois, somados o quantitativo de benefícios disponibilizado aos conjuntos bolsa-nacional, bolsa-internacional, bolsa-olímpica e bolsa pódio, chega-se ao montante de 42.665 (92\%) atletas beneficiados, contra apenas $3.581(8 \%)$ do esporte de base, caracterizada pela bolsa de base e estudantil.

Corrêa et al. (2014) dizem que não há um equilíbrio entre as diferentes categorias, sendo possível pensar numa organização piramidal com deformações:

Onde se tem um financiamento estreito para a iniciação esportiva na base da pirâmide. Seguindo por uma lateral mais larga preenchida pelos atletas que foram absorvidos para uma especialização do treinamento em nível de rendimento. Já no topo da pirâmide novamente se apresenta um estreitamento, visto que contempla uma quantidade pequena de atletas que conseguem galgar o nível olímpico (CORRÊA et al., 2014, p. 6).

O crescimento acentuado em favor da pirâmide, notadamente a partir do ano de 2010 (categoria nacional) e 2011 (categoria internacional), pode ser reflexo da "conquista" do direito de sediar os Jogos Olímpicos de 2016, haja vista a prioridade do governo federal em avançar posições no quadro de medalhas. Nesse sentido, é preciso registrar que a Lei $n^{0} 12.395 / 2011$ limitou em $15 \%$ do valor total do Programa para os participantes de modalidades individuais e coletivas que não fizeram parte do programa olímpico.

Para corroborar com a afirmação acima, registra-se que o percentual de beneficiados apenas das modalidades olímpicas foi de $83 \%$ do total de bolsas concedidas. Subtraindo do quantitativo geral chegamos ao número de apenas $17 \%$ para as modalidades não-olímpicas.

Diante das informações coletadas e considerando o período do estudo, percebe-se claramente que foco do Bolsa Atleta é no investimento de atletas já prontos, e que compõem o programa olímpico, em detrimento da formação. Isso mostra a fragilidade desse programa governamental, uma vez que os principais resultados obtidos nas últimas três olimpíadas oscilam consideravelmente, ora com melhora, ora com piora em alguns esportes, conforme evolução histórica apresentada pela tabela 4, a seguir. 
Tabela 4 - Medalhas conquistadas por atletas brasileiros nos Jogos Olímpicos de Pequim 2008, Londres 2012 e Rio de Janeiro 2016.

\begin{tabular}{|c|c|c|c|}
\hline \multicolumn{4}{|c|}{ Principais resultados olímpicos (evolução histórica) } \\
\hline Modalidade & $\begin{array}{c}\text { Pequim } 2008 \\
\text { (277atletas/36bolsas) }\end{array}$ & $\begin{array}{c}\text { Londres } \mathbf{2 0 1 2} \\
\text { (259atletas/111 bolsas) }\end{array}$ & $\begin{array}{c}\text { Rio de Janeiro } 2016 \\
\text { (465atletas/358bolsas) }\end{array}$ \\
\hline Atletismo & 06 finais/01 ouro & 03 finais & 06 finais/01 ouro \\
\hline Basquete & - & 01 quartas & - \\
\hline Boxe & 02 quartas & 02 bronzes/01 prata & 01 ouro \\
\hline Canoagem & - & - & $\begin{array}{c}01 \text { final } / 01 \text { bronze } / 02 \\
\text { pratas }\end{array}$ \\
\hline Ciclismo & - & - & $7^{o}(\mathrm{~F})$ \\
\hline Esgrima & - & - & 02 quartas \\
\hline Futebol & 01bronze/01 prata & 01bronze/01 prata & 01 ouro \\
\hline Ginástica artística & 05 finais & 01 ouro & $\begin{array}{c}09 \text { finais/01 bronze/02 } \\
\text { pratas }\end{array}$ \\
\hline Ginástica rítmica & - & - & $9^{\circ}(\mathrm{F})$ \\
\hline Handebol & - & 01 quartas & 02 quartas \\
\hline Hipismo & 03 finais & 01 final & 01 final \\
\hline Judô & 03 bronzes & 03 bronzes/01 ouro & 02 bronzes/01 ouro \\
\hline Levantamento & $10^{\circ}(\mathrm{M})$ & $8^{\circ}(\mathrm{F})$ & $5^{\circ}(\mathrm{M})$ \\
\hline Luta olímpica & - & - & 02 quartas \\
\hline Maratona aquática & $5^{\circ}(\mathrm{F})-7^{\circ}(\mathrm{F})$ & - & $10^{\circ}(\mathrm{F}) / 01$ bronze \\
\hline Natação & $\begin{array}{c}05 \text { finais/01 bronze/01 } \\
\text { ouro }\end{array}$ & $\begin{array}{c}03 \text { finais/01 bronze/01 } \\
\text { prata }\end{array}$ & 08 finais \\
\hline Pentatlo moderno & - & 01 bronze & - \\
\hline Polo aquático & - & - & 2 quartas \\
\hline Remo & 02 quartas & - & - \\
\hline Saltos ornamentais & - & - & 01 final \\
\hline Taekwondo & 02 quartas/01 bronze & 01 semi & 02 quartas/01 bronze \\
\hline Tênis & 01 quartas & 01 quartas & 03 quartas \\
\hline Tênis de mesa & - & 02 quartas & 02 quartas \\
\hline Tiro esportivo & - & - & 01 prata \\
\hline Vela & $\begin{array}{c}03 \text { finais/01 bronze/01 } \\
\text { prata }\end{array}$ & 01 bronze & 01 ouro \\
\hline Vôlei & 01prata/01 ouro & 01 prata/01 ouro & 01 quartas/01ouro \\
\hline Vôlei praia & 01bronze/01 prata & 01 bronze/01 prata & 01 prata/01 ouro \\
\hline
\end{tabular}

Fonte: http://www.olympic.org/beijing-2008-summer-olympics; http://www.olympic.org/london-2012-summer-olympics. https:// www.rio2016.com/calendario-e-resultados. Elaboração dos autores (2016). 
Os dados da tabela 4 induzem a construção de indicadores no sentido de homogeneizar as informações apresentadas, assim optou-se por realizar dois movimentos, sendo o primeiro a comparação dos resultados de Pequim/Londres e, posteriormente, Londres/ Rio. O segundo movimento fora a construção das categorias, as quais têm relação com a evolução histórica dos esportes, isto é, se melhoraram, se mantiveram o desempenho, ou se pioraram.

No comparativo Pequim/Londres, 19 modalidades tiveram seu desempenho avaliado, sendo que 07 esportes pioraram seus resultados, 06 mantiveram em Londres o mesmo desempenho de Pequim e outros 06 melhoraram seus resultados. Em termos de delegação, o Brasil foi representado em Pequim por 277 atletas, destes, 36 bolsistas (13\%). Já em Londres o número de atletas brasileiros fora menor (259), contudo, cresceu o número de bolsista, totalizando $111(42 \%)$.

Este considerável aumento de um ciclo para o outro se deve pela atualização do Programa Bolsa Atleta, por meio da Lei no 12.395/2011, uma vez que esta possibilitou aos atletas com patrocínio privado serem beneficiados. Não obstante, no momento que realizamos a junção dos ciclos olímpicos, a proporção de atletas bolsistas participantes dos ciclos Pequim/Londres é de apenas $27 \%$, o que culmina com sua baixa representatividade.

Os números Londres/Rio são melhores em relação ao ciclo anterior, o que proporcionou 26 modalidades figurarem na relação dos principais resultados alcançados. Assim, temos que 16 esportes melhoraram seu desempenho, 8 pioraram e 2 mantiveram sua performance semelhante aos jogos de Londres. A delegação brasileira nos Jogos do Rio de Janeiro foi a maior de toda história contando com 465 atletas, destes, 358 são bolsistas, percentual próximo de $77 \%$.

Os dados da tabela 4 ainda possibilitam uma análise comparativa entre o número de medalhas conquistadas por bolsistas nos Jogos de Pequim, Londres e Rio de Janeiro. Há uma notável evolução entre os ciclos, isto é: em 2008 o país conquistou 15 medaIhas, sendo 07 por bolsistas; em 2012, das 17 medalhas, 10 foram por atletas vinculados ao programa. Já nos Jogos do Rio de Janeiro todas as 19 medalhas foram de bolsistas. Os percentuais saíram de 46\%, em 2008, para 58\%, em 2012, e culminando com 100\%, em 2016. Na aglutinação dos ciclos percebe-se que dos 51 pódios brasileiros $70 \%$ foram de bolsistas do programa.

Não obstante, voltamos a questionar o programa em sua abrangência, pois, se compararmos o total de bolsas, desde a sua implementação, em 2005 (46.246), com o número de pódios conquistados pela delegação brasileira ao longo do período, estes representaram pífios $0,11 \%$ (51 medalhas) 27 .

Por fim, vale o debate sobre o posicionamento brasileiro no quadro de medalhas em comparação aos demais países, em que se nota que nos últimos Jogos Olímpicos, o Brasil ficou apenas nas $23^{\circ}, 22^{\circ}$ e $13^{\circ}$ colocações no quadro geral de medalhas, portanto, a meta adotada pelo Governo Federal, em colocar o país no top 10 do ranking de medalhas

27 Cabe o registro que um mesmo atleta pode ter recebido a bolsa por mais de um ano, bem como ter ganhado mais de uma medalha ao longo do ciclo. 
olímpicas não foi atingida, embora houvesse todas as estratégias adotadas para atingir este fim e o grande quantitativo de recursos para o esporte olímpico, em especial no último ciclo (TEIXEIRA, MATIAS E MASCARENHAS, 2013).

\section{CONSIDERAÇÕES FINAIS}

Ao se concluir este trabalho, reitera-se que seu objetivo foi propor a continuidade do debate do Bolsa Atleta, não esgotando as possibilidades de estudo de tal temática, visto que, considerando o volume de recursos disponibilizados, no qual se verificou crescimento ao longo dos anos, a representatividade considerável do Bolsa Atleta no orçamento do Ministério do Esporte, assim como a evolução do número de beneficiados, nota-se que o programa ainda possui abrangência restrita, pois apenas $50 \%$ dos atletas classificados nos três últimos Jogos Olímpicos são bolsistas e, ainda do total de benefícios, somente 0,11\% culminou com pódio para o país.

Destaca-se também a intencionalidade do programa na centralidade dos recursos na ponta da pirâmide esportiva, em detrimento da formação, dado que $92 \%$ das bolsas pagas contemplaram categorias-membros do programa olímpico. Isso demonstra fragilidade do Bolsa Atleta, uma vez que os resultados obtidos nas últimas três olimpíadas oscilaram consideravelmente, principalmente das modalidades mais privilegiadas e com maior possibilidade no quadro de medalhas dos jogos, tal performance pode estar relacionada a alguns aspectos também identificados por Guimarães (2009), e comentados a seguir.

O programa não tem por fundamentação a continuidade como forma de manutenção ou melhora da qualidade dos esportistas, tendo em vista que pouquíssimos atletas receberam a bolsa por três ou quatro anos consecutivos28, por exemplo, caso determinado atleta já contemplado pelo benefício sofrer uma lesão em fases preparatórias, afastando-se das competições por um considerável intervalo de tempo, com certeza será prejudicado, pois, não se qualificará ao benefício no ano seguinte.

Tal afirmação se relaciona com a baixa abrangência do programa identificada ao longo do estudo, além da ausência de fiscalização por parte do Ministério do Esporte, ocasionando inúmeras denúncias de atletas contemplados que sequer disputaram alguma competição no ano-referência ${ }^{29}$, em prejuízo a outros que poderiam ter sido contemplados.

Portanto, a estratégia de privilegiar os atletas "prontos" pode até garantir alguns bons resultados no curto prazo, porém dificulta à manutenção do país como uma potência esportiva, se for esse mesmo o objetivo governamental, tal afirmativa se convalida principalmente por meio de estudos por série histórica como o caso desse trabalho.

28 Somente os atletas da categoria Olímpica podem automaticamente ter o benefício por quatro anos, renovando a cada ano.

29 Eventos de "fundo de quintal" tiveram a chancela de "internacionais" para aumentar o valor da bolsa para contemplados de fachada. E isso ocorre com a omissão do Conselho Nacional do Esporte, que tem a obrigação de fiscalizar as ações do Ministério. Disponível em http://josecruz.blogosfera.uol.com.br Acesso em: 22 set. 2016. 
Para a superação de tais mazelas, devem-se retomar as estratégias definidas a partir da I e II Conferência Nacional do Esporte, ou seja, estabelecer um Sistema Nacional do Esporte, que tenha como princípio assegurar o esporte como direito de todos, e não apenas aqueles que compõem o programa olímpico, contando, ainda, com investimentos em infraestrutura, na formação inicial e continuada de profissionais, no estabelecimento de um sistema nacional descentralizado de financiamento, associado com o conhecimento científico produzido nas universidades.

\section{REFERÊNCIAS}

ALMEIDA, B. S. O financiamento do esporte olímpico e as suas relações com a política no Brasil. 2010. 119f. Dissertação (Mestrado em Educação Física) - Departamento de Educação Física, Universidade Federal do Paraná, Curitiba.

ATHAYDE, P. F. A. O "lugar do social" na Política de esporte do governo Lula. Revista SER Social, Brasília, v. 13, n. 28, p. 184-209, jan./jul. 2011.

- A disputa pelo fundo público no âmbito do financiamento esportivo

brasileiro. In: XVIII Congresso Brasileiro de Ciências do Esporte e V Congresso Internacional de Ciências do Esporte, 2013, Brasília.

BRACHT, V.; ALMEIDA, F. Q. A política de esporte escolar no Brasil: a pseudovalorização da Educação Física. Revista Brasileira de Ciências do Esporte, Campinas, v. 24, p. 87-101, 2003.

BRASIL. III Conferência Nacional do Esporte: documento final. Brasília: Ministério do Esporte, 2010.

. Lei $\mathbf{n}^{\mathbf{0}} \mathbf{1 0 . 8 9 1 / 0 4}$, de 09 de julho de 2004. In: http://www2.esporte.gov.br/arquivos/ snear/bolsaAtleta/lei1089109Juho2004.pdf. Acesso em: 22 ago. 2014.

. Lei $\mathbf{n}^{\mathbf{0}}$ 12.395/11, de 16 de março de 2011. In: http://www.planalto.gov.br/ ccivil_03/_ato2011-2014/2011/lei/l12395.htm. Acesso em: 22 ago.2014.

BOSCHETTI, I. Avaliação de políticas, programas e projetos sociais. In: Serviço Social:

Direitos Sociais e Competências Profissionais. Brasília, CFESS, ABEPSS, 2009.

CASTELAN, L. P. As conferências nacionais do esporte na configuração da política esportiva e de lazer no governo Lula (2003-2010). Campinas, 2011.188f. Dissertação (Dissertação de Mestrado em Educação Física) Faculdade de Educação Física, UNICAMP, 2011.

CASTELLANI FILHO, L. O Estado Brasileiro e os Direitos Sociais: O Esporte. In: HÚNGARO, Edson Marcelo; DAMASCENO, Luciano Galvão; GARCIA, Carla Cristina (Orgs.). Estado, política e emancipação humana: lazer, educação, esporte e saúde como direitos sociais. Santo André, SP: Alpharrabio, 2008. p. 129-144.

CHARNOV, B. H.; MONTANA, P. J. Administração. São Paulo: Saraiva, 2001.

CORRÊA, A. J. Financiamento do Esporte Olímpico de Verão Brasileiro: Mapeamento Inicial do Programa "Bolsa Atleta". Pensar a Prática, Goiânia, v. 17, n. 4, out/dez 2014. COSTA, L. (Org.). Atlas do Esporte no Brasil. Rio de Janeiro: CONFEF, 2006. 
FAGNANI, E. Avaliação do ponto de vista do gasto e financiamento das políticas públicas. In: RICO E, organizadora. Avaliação de políticas sociais: uma questão em debate. 6 . ed. São Paulo: Cortez: Instituo de Estudos Especiais, 2009. p. 119-130.

GUIMARÃES, A. S. Bolsa-Atleta eleva o desempenho de seus beneficiários? Análise do Período 2005/2008. Consultoria do Senado Federal - Centro de Estudos, 2009.

SALVADOR, E. Fundo público no Brasil: financiamento e destino dos recursos da seguridade social (2000 a 2007). 2008. 395f. Tese (Doutorado em Política Social) - Departamento de Serviço Social, Universidade de Brasília - UnB, Brasil, 2008.

TEIXEIRA, M. R; MATIAS, W. B; MASCARENHAS, F. O financiamento do esporte olímpico no Brasil: uma análise do ciclo de Londres (2009-2012). Revista de Ciencias Sociales de la Universidad Arturo Prat, 2013.

VERONEZ, L. F. C. Quando o Estado joga a favor do privado: As políticas de esporte após a Constituição Federal de 1988. Campinas, 2005. 370f. Tese (Doutorado em Educação Física) Faculdade de Educação Física, UNICAMP, 2005.

Recebido em: outubro/2016 Aprovado em: março/2017 